\title{
Etnobotânicas da Recusa: Metodologias de Engajamento com a Resistência Humana-Implantada*
}

\author{
Ruth Goldstein ${ }^{1}$ \\ Tradutor: Daniel Belik ${ }^{2}$ \\ Revisor: Daniel Silva ${ }^{3}$ \\ ${ }^{1}$ University of Wisconsin, Madison, WI, EUA \\ ${ }^{2}$ Universidade Federal de Rondônia, Porto Velho, RO, Brasil \\ ${ }^{3}$ Universidade Federal de Santa Catarina, Florianópolis, SC, Brasil
}

\section{Resumo}

Este artigo examina o momento acadêmico da "Virada Vegetal" ou o que Natasha Myers (2015) chamou "The Plant Turn" na antropologia norte-americana e na filosofia. É uma oportunidade de destacar o legado e continuar contribuições de cosmologias indígenas para a teoria social, sublinhando como as pessoas "dentro-e-fora" do pensamento ocidental há muito pensam em "tornar-se-com" as plantas. Considerando as ramificações disciplinares e as políticas das relações botânico-humanas, quando os curandeiros e os praticantes de plantas seguem, em grande parte, não citados nessas discussões, este artigo envolve vários pensadores: Audra Simpson sobre uma etnográfica recusa, Emilia Sanabria sobre a Ayahuasca e as ciências psicodélicas, Michel-Rolph Trouillot sobre o "Savage Slot", a crítica de Zoe Todd às práticas citacionais e à contínua eliminação de pensadores indígenas, o esforço conjunto de Davi Kopenawa e Bruce Albert, assim como o trabalho de Natasha Myers e Michael Marder. A análise articula possíveis abordagens em etnobotânicas e em metodologias de recusa com vistas ao respeito à resistência humano-implantada.

Palavras-chave: Virada Vegetal. Etnobotânica. Indigeneidade. Política da Citação.

\section{Ethnobotanies of Refusal: Methodologies in Respecting Plant(ed)-Human Resistance}

\begin{abstract}
This article examines the scholarly moment of the "Botanical Turn" or what Natasha Myers (2015) has called "The Plant Turn" in North American anthropology and philosophy. It represents an opportunity to highlight the legacy and continued contributions of indigenous cosmologies to social theory, underlining how people within-and-without Western thought have long thought about "becoming-with" plants. Considering the disciplinary as well as the political ramifications of botanico-human relations when plant healers and practitioners go largely un-cited in these scholarly discussions, this article engages multiple thinkers: Audra Simpson on ethnographic refusal, Emilia Sanabria on Ayahuasca and the psychedelic sciences, Michel-Rolph Trouillot on the "Savage Slot", Zoe Todd's critique of citational practices and continued erasure of indigenous thinkers, Davi Kopenawa and Bruce Albert's joint effort, as well as the work of Natasha Myers and Michael Marder. The analysis frames possible approaches in ethnobotanies and methodologies of refusal to respecting plant(ed)-human resistance.
\end{abstract}

Keywords: The Plant Turn. Ethnobotany. Indigeneity. Politics of Citation. 


\section{Introdução}

Por que só agora? Depois de tanto tempo, vocês todos querem conhecer a floresta e suas plantas como seres sencientes, conscientes... Nós sempre as consideramos parte de nossa família - as árvores, a ayahuasca, castanha-do-brasil, tudo! E agora vocês querem conversar sobre plantas medicinais... Do que estamos falando aqui? A outra versão moderna da biopirataria? (Txai Tuwe, Huni Kuĩ)

Figura 1 - Taxi Tuwe

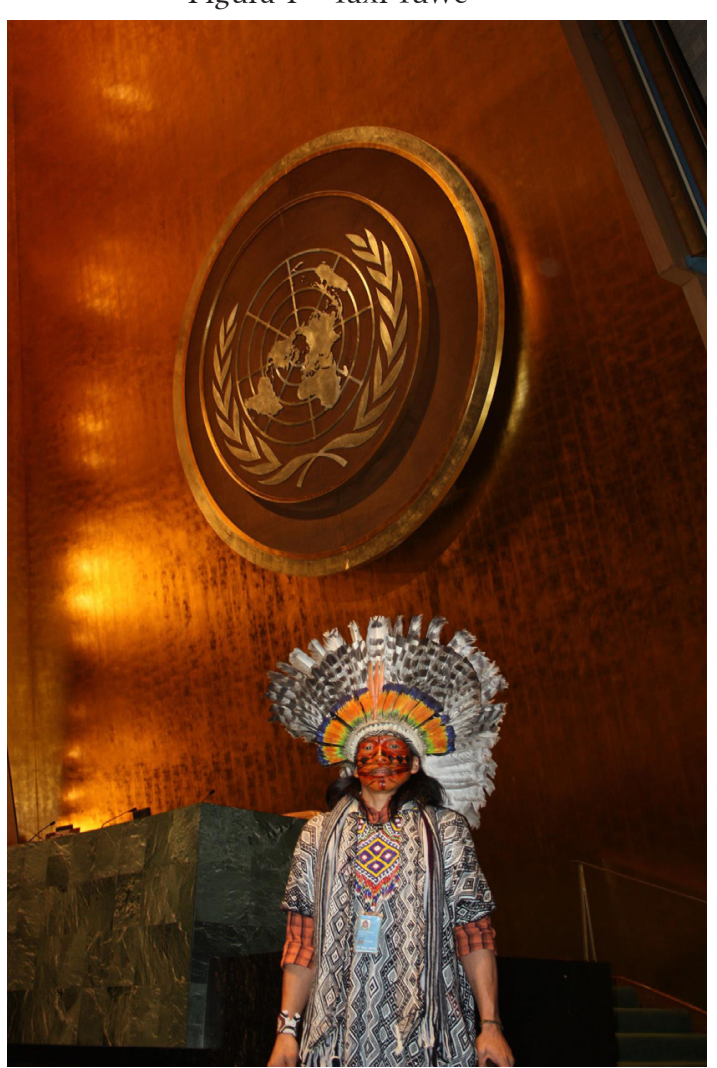

Fonte: Txai Tuwe no Congresso das Nações Unidas em 2013

Txai Tuwe, um jovem xamã Huni Kuĩ, se coloca diante de mim na maloca. Ele estava, justamente, questionando meus interesses pelas plantas medicinais, pela Floresta Amazônica e pela senciência da vida botânica. Sua principal preocupação era com a biopirataria: o roubo do material biológico e seu conhecimento tradicional associado. Estamos em abril de 2011, em uma reunião organizada pela Comissão Pró-Índio do 
Acre (CPI), no Estado do Acre, perto da fronteira com o Peru e a Bolívia. "Txai" designa alguém que é "mais do que um amigo, mais do que um irmão" - alguém que reconhece uma conexão entre a vida humana e a não humana, que se dedica integralmente a buscar melhorar a vida do outro (CARNEIRO DA CUNHA; ALMEIDA, 2002). Malu Ochoa, minha vizinha que logo moraria junto comigo, nos havia introduzido. Como diretora executiva da Organização Não Governamental (ONG) CPI, o trabalho de Ochoa consiste em propiciar que lideranças indígenas Brasil afora e também na tríplice fronteira se reúnam.

Figura 2 - Árvore e flor de abricó-de-macacão

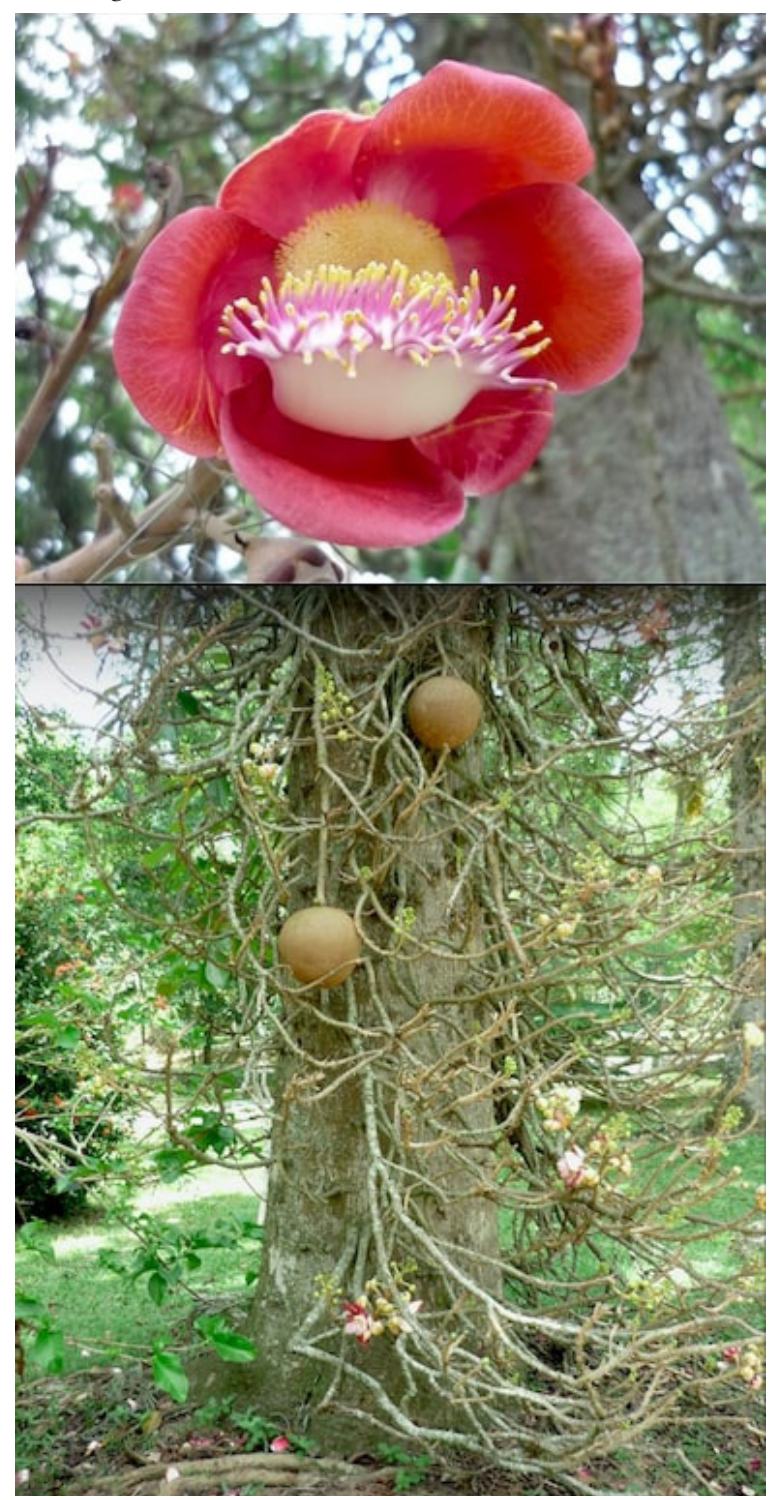

Fonte: Extraída da obra traduzida

Txai Tuwe oferece um novo lugar para conversarmos. A maloca é, geralmente, reservada para reuniões importantes que acontecem ao longo do dia e para cerimônias de ayahuasca à noite. Buscamos um canto embaixo de um jacarandá em flor, com flores de abricó-de-macacão perfumando o ar (ver Figura 2). O terreno da Comissão Pró-Índio é um oásis verde em meio aos vastos campos desmatados para cultivo de gado e a uma 
madeireira. Sua existência exemplifica a resistência dos povos indígenas amazônicos que se veem literalmente na encruzilhada da infraestrutura desenvolvimentista: logo ao lado da Rodovia Transacreana, algumas centenas de metros da recentemente construída Rodovia Interoceânica ${ }^{1}$.

O fluxo transfronteiriço aumentou em intensidade depois da construção de novas estradas na Amazônia. Não é raro ouvirmos o barulho dos treminhões carregados de tora de madeira passando.

Figura 3 - Treminhão de Madeira

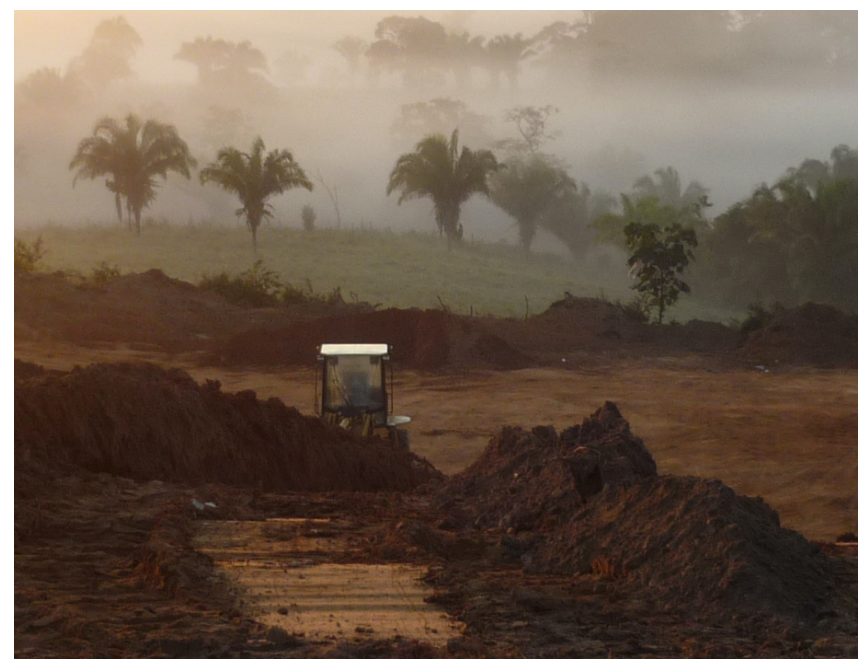

Fonte: Extraída da obra traduzida

"As lideranças indígenas estão preocupadas com as mudanças trazidas por esses empreendimentos para a zona de fronteira", me diz Txai Tuwe em referência à Rodovia Interoceânica, que interliga o Estado do Acre com cidades peruanas. As preocupações vão desde a violência causada por traficantes de pessoas e de drogas que cooptam indígenas nas aldeias até o desmatamento e a pilhagem feita pela biopirataria.

Figura 4 - Sistema Integrado de Segurança Pública

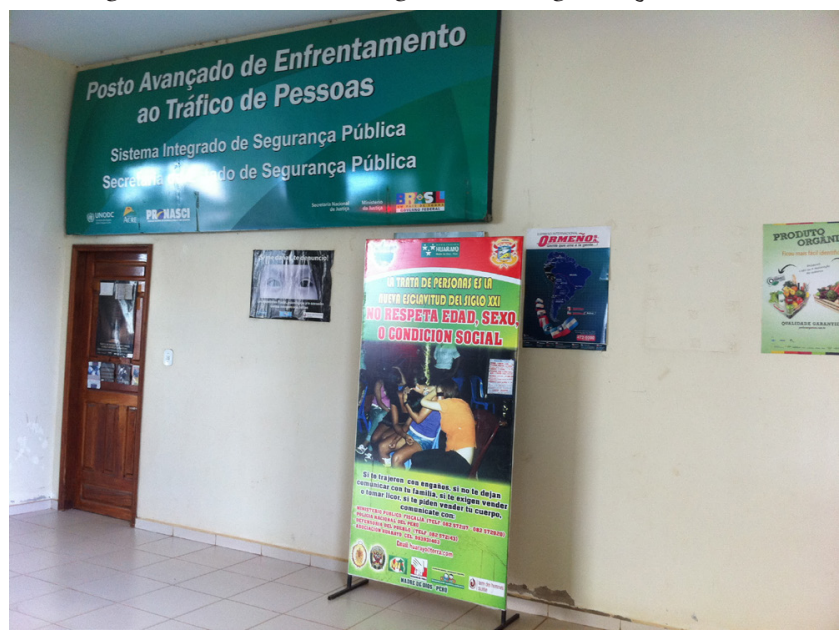

Fonte: Extraída da obra traduzida

A Rodovia Transacreana corta o Estado do Acre por, aproximadamente, 94 km. A Rodovia Interoceânica liga o Atlântico brasileiro à costa do Pacífico, no Peru, em um trajeto de mais de $5.000 \mathrm{~km}$ de extensão. 
Durante a COP9 da Convenção para Diversidade Biológica (CDB), realizada em Bonn, na Alemanha, Txai Tuwe participou como um dos representantes indígenas da Amazonlink.org, uma pequena ONG brasileira que se dedica a proteger os direitos indígenas. Eles coordenaram um workshop intitulado "Aldeias Vigilantes" (ver Figura 5), empoderando comunidades com conhecimento sobre seus direitos de compartilhar - ou não compartilhar - informações sobre seus conhecimentos das plantas e das práticas medicinais.

Figura 5 - Aldeias Vigilantes

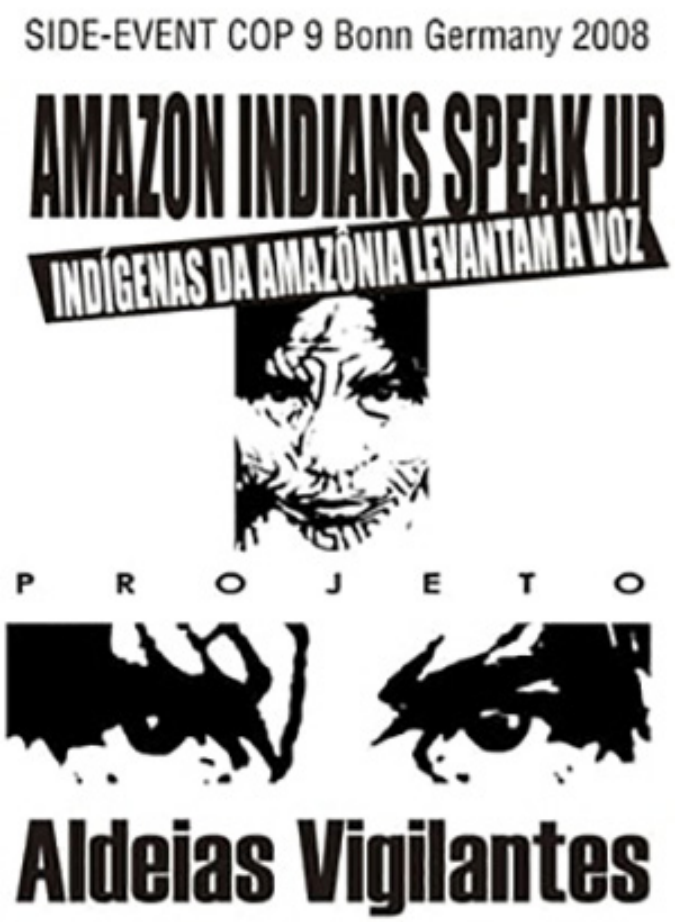

Project Watchful Villages

Fonte: Extraída da obra traduzida

Txai Tuwe explicou que quando alguém que entende de botânica, como eu, chega de um centro cosmopolita perguntando sobre plantas, sua primeira reação é saber o porquê de a pessoa estar buscando esse conhecimento sobre plantas amazônicas, sua história e aplicações etnomedicinais. Para as aldeias indígenas cujas plantas medicinais e o conhecimento indígena circulam no mercado global, a biopirataria é apenas uma continuação da dominação colonial, que visa apenas ao lucro e não leva em consideração o conhecimento indígena, a repartição de benefícios ou o consentimento informado (DANLEY, 2012; SHIVA, 1997; TUSTIN, 2006). A prática relacionada à bioprospecção formaliza direitos intelectuais de propriedade, patenteando produtos comerciais desenvolvidos a partir de material e de conhecimento etnobiológico - mas quase sempre sem qualquer repartição de benefícios substantiva (SHIVA, 1997). O "Consentimento Livre, Prévio e Informado (CLPI)" está protocolado nas Nações Unidas desde 1991, mas implementá-lo ainda continua a ser um desafio. As discussões sobre como fazê-lo persistem. A tática perseguida pela Amazonlink.org é trabalhar diretamente com as 
comunidades. Governos tendem a implementar mais as políticas que seus representantes demandam. O ano de 2011 marcou o desmonte da biopirataria levado a cabo pelo governo brasileiro (ELLSWORTH, 2010) em ações que reconheceram as corporações farmacêuticas como os principais culpadas (INDRIUNAS, 2003). Embora o golpe de 2016 que concedeu o controle do executivo brasileiro a Michel Temer e as eleições de 2018 que elegeram o candidato de direita Jair Bolsonaro tenham alterado radicalmente a paisagem política brasileira, meu interesse ainda se concentra em como investigar o entrelaçamento entre plantas e direitos intelectuais indígenas na luta pela garantia da soberania dos seus territórios tradicionais (DANLEY, 2012; GOLDSTEIN, 2020; PANTOJA, 2008; PANTOJA; MEYER, 2014; SCHMIDLEHNER, 2011; TUSTIN, 2006). Os métodos indígenas de coleta e seu conhecimento sobre as plantas quase sempre contribuíram para o desenvolvimento da indústria farmacêutica ocidental (BALICK; COX, 1997; DUKE, 1992). Sem sombra de dúvida, integrantes das comunidades podem se recusar a falar com pesquisadores - biopiratas ou não - mas a vulnerabilidade econômica geralmente fala mais alto do que as práticas de conservação. Este artigo foi instigado pelas provocações iniciais de Txai Tuwe sobre em que medida meus interesses pela senciência das plantas podem representar também "uma espécie de biopirataria". A partir do corpus teórico que se apoia no que Natasha Myers cunhou de "virada vegetal" dentro das pesquisas antropológica e filosófica de tradição ocidental, vejo aqui uma oportunidade de frisar o legado e a contribuição continuada dos conhecimentos indígenas para a teoria social, ressaltando como pessoas tanto dentro como fora da tradição de pensamento crítico na América do Norte e da Europa há tempos já praticavam o “estar com e junto das plantas" (MYERS, 2015). Estou levando em conta as ramificações, tanto políticas como disciplinares, das relações humano-botânicas quando xamãs e praticantes - especialmente indígenas - não são citados pelas discussões acadêmicas. Ao incorporar a inestimável contribuição teórica proporcionada pelos estudos de cientistas europeus e americanos e de outros acadêmicos, proponho uma "virada etnobotânica" que saiba reconhecer o campo preexistente do pensamento acerca da senciência das plantas, já há muito semeado pelas práticas etnobotânicas indígenas dos xamãs e por outros conhecedores mundo afora. Essa abordagem pretende, ao mesmo tempo, reconhecer e se engajar com os interesses políticos ancorados no conhecimento botânico. No Brasil, a luta indígena pelo seu território e pela soberania política ganhou mais força à medida que se atrelou ao patrimônio cultural. Muitos antropólogos brasileiros estão diretamente comprometidos com esse debate político-legal (CARNEIRO DA CUNHA; ALMEIDA, 2002; PANTOJA, 2008; LABATE, 2010; 2012). Se o governo considera que determinada planta (ou animal) e sua prática relacionada são patrimônios culturais específicos de determinada área, a luta pelos direitos da terra dessas pessoas se torna mais factível. Se a biopirataria extorque o patrimônio cultural, isso irá, inevitavelmente, afetar os esforços das comunidades indígenas em demarcar suas próprias terras, refletindo desigualdade de poder. Como Txai Tuwe sempre me lembrava, durante o ano de 2018, as comunidades indígenas - e não somente a sua - sempre consideraram as plantas como seres conscientes, comunicativos e como parte de sua família. Acadêmicos indígenas, como Zoe Todd (2016), Elizabeth Hoover (2017), Robin Wall Kimmerer (2013), Enrique Salmón (2000), Rosalyn LaPier (2005; 2016) e Whyte (2013), apenas para citar alguns, escreveram veemente sobre 
ecologias de parentesco concêntrico nas relações vitais de humanos e não humanos. Todd (2016) apontou ainda o racismo institucional na política de citações acadêmicas. Citando Dwayne Donald, um acadêmico da etnia Métis, Todd se fia na "relacionalidade ética", definida por ele como "[...] um entendimento ecológico da relacionalidade humana que não nega a diferença, mas que visa mais propriamente entender a maneira como nossas diversas histórias e experiências de vida nos posicionam em relação ao outro" (DONALD, 2012, p. 535). Essa maneira de se relacionar acaba por incrementar uma "reciprocidade de pensamento" como parte de um comprometimento filosófico desses dois acadêmicos Métis. Trata-se de uma abordagem para produção do conhecimento que leva a "ecologia" das citações a sério, considerando os modos de colaboração, análise e de existência que poderiam florescer caso os mestres indígenas fossem citados nas discussões teóricas da academia, especialmente quando se trata do modo de vida não humano e do conhecimento extraído dele. Ao trazer a "relacionalidade ética" para as pesquisas centradas na relação humano-planta, examino o que uma etnobotânica e antropóloga não indígena como eu, educada na tradição ocidental de autoria (específica) individual, pode aprender com intelectuais indígenas, bem como com o modo das plantas (e micorrizas) estarem no mundo (GOLDSTEIN, 2009; MARDER, 2012; MYERS, 2015, 2016; TSING, 2015). O objetivo é trabalhar em direção a métodos etnográficos e etnobotânicos mais colaborativos. Tal atitude pode resultar em uma recusa em disseminar informações etnobotânicas partilhadas comigo e citar com relacionalidade ética. Quando estamos falando de direitos de propriedade intelectual, definir quem "possui" as ideias depende inteiramente daquele de quem "pensou" primeiro ou foi seu primeiro "autor". O reconhecimento dos direitos de propriedade intelectual para intelectuais indígenas, acadêmicos ou não, tem impacto direto em suas práticas culturais, bem como nos direitos políticos e territoriais - em outras palavras, em sua própria existência.

\section{Enraizando a Virada Ontológica e Etnobiológica}

Quando primeiro falei com Txai Tuwe, eu me lembrei das preocupações de Audra Simpson "Sobre a recusa etnográfica: Indigenismo, 'voz' e cidadania colonial" (SIMPSON, 2007). Passamos a imaginar como seria, para as comunidades indígenas das Américas, partilhar experiências e estratégias de resistência. Txai Tuwe se pergunta: "o que será que os etnobotânicos se recusariam a dizer sobre as plantas e pessoas?". Os esforços intensivos necessários para detalhar e identificar marcadores e usos medicinais das plantas amazônicas indicam que mesmo se alguém não pretenda, necessariamente, incrementar a biopirataria, ainda é possível divulgá-la sem consentimento acordado. Nota-se, porém, que recusar ou confundir o pesquisador estrangeiro sempre foi um modo de resistência praticado pelos indígenas. O artigo do filósofo Michael Marder (2012) "Resista como uma planta! Sobre a vida vegetal dos movimentos políticos" segue o mesmo curso de análise. Sua reflexão sobre as estratégias das plantas e a contribuição intelectual dos movimentos sociais abre a possibilidade de metodologias e etnobotânicas da recusa ao se engajar com a resistência humano-implantada. Marder é um dos intelectuais europeus (neto de uma brasileira) mais vanguardistas nas discussões relativas à existência das 
plantas no mundo vistas por meio da metafísica ocidental (MARDER, 2012; 2013; 2014). Concomitantemente, Natasha Myers, em sua abordagem decolonial feminista ao que ela "meio despudorada, meio seriamente" chama de "Plantropoceno" (MYERS, 2016; 2017a), alarga esse campo de investigação sociobotânico. Esquadrinhando um caminho para se debater uma "plantropologia" (MYERS, 2015), Myers (2017b, p. 2) insiste em olhar para as formas de conhecimento capazes de expor as lógicas coloniais e extrativistas das ciências, ao mesmo tempo que obrigam cientistas, seu público, governos e a indústria a se tornarem mais responsáveis por formular melhores perguntas e cultivar modos de investigação mais robustos. Para Myers (2017b, p. 3), essa é uma das formas de responder - à e com - àqueles mais atingidos pelas mudanças climáticas, apoiando

[...] a criação de formas de conhecimento que podem nos ajudar a argumentar contra regimes de evidência constrangedores, deslocar ideias perturbadoras sobre quais modos de atenção, objetos, métodos e dados são próprios às ciências e romper com pressuposições sobre quais conhecimentos são mais válidos do que outros.

É partindo desse espírito que escrevo sobre e examino as diferentes formas de produção, de ajuste e de compartilhamento de conhecimento que podem impactar as reivindicações indígenas por autoctonia política e territorial. Não é somente no campo das ciências sociais e humanas que o estudo das plantas voltou a ganhar proeminência. Ou talvez seja o caso de ter surgido um reconhecimento em outros corredores da ciência ocidental de que "a planta", como objeto de análise, tornou-se frutífera novamente. Essa tendência vai de encontro às noções fundacionais que encontramos em Aristóteles no "De anima", em que plantas são vistas como não tendo senciência em decorrência de sua ausência de movimento. A virada vegetal caminha junto com a virada ontológica na antropologia e participa mais amplamente, nas ciências sociais, das discussões teóricas sobre a vida multiespécie (HARAWAY, 2007; KIRKSEY; HELMREICH, 2010; KOSEK, 2010). Essas ondas consecutivas de novas ideias criam o potencial de reconhecer noções indígenas da relação pessoa-planta (HALL, 2011; KOPENAWA; ALBERT, 2013; VIVEIROS DE CASTRO, 2004), construindo pontes teóricas e solidárias que perpassam diferenças raciais e étnicas. A preocupação, no entanto, permanece no sentido de que a profusão de viradas teóricas, tanto na Europa como nos Estados Unidos, pode perpetuar continuamente uma prática cultural que extrai, mas não reconhece nem cita esses mestres indígenas, além de contribuir com a biopirataria. Se as vozes indígenas forem deixadas de fora da conversa, então há pouca chance de uma reflexão crítica sobre o paradigma colonial - se ainda existe a vontade de superá-lo - tanto nas ciências sociais quanto nas áreas de biologia vegetal, nos direitos de propriedade intelectual e na área farmacêutica. Ainda que as severas críticas da intelectual Métis Zoe Todd à virada ontológica - em cujos termos "ontologia é apenas outro nome para colonialismo" (TODD, 2016) - não tenha sido notada, seu foco está mais direcionado às aulas de Latour sobre Gaia do que aos antropólogos latino-americanos que levam a sério as cosmologias ameríndias e seus professores (BLASER, 2013; DE LA CADENA, 2010; 2015; VIVEIROS DE CASTRO, $2004 ; 2014)$. Na próxima seção, enxerto partes das viradas vegetal e ontológica de modo a fertilizar uma virada etnobiológica a ser inserida dentro dos estudos pós-coloniais, oferecendo possíveis maneiras de engajamento acadêmico e "responsa-habilidade" 
(HARAWAY, 2007) nas análises antropológicas centradas no mundo vegetal. "Como entrevistar uma planta" de John Hartigan (2017) e a atenção dispensada a outras formas de estratégias fitocomunicativas (SCHULTHIES, 2019) nos vêm logo à mente. Menciono ainda a ayahuasca como exemplo de como determinadas plantas estão intimamente envolvidas com as pessoas na sobrevivência colaborativa (TSING, 2015), ao mesmo tempo em que representam o entrelaçamento dos pilares materiais-semióticos da virada etnobotânica e consideram as reivindicações indígenas por conhecimento tradicional e reconhecimento territorial.

\section{Ayahuasca: uma planta política, espiritual e psicodélica}

No dia em que conversava com Txai Tuwe embaixo da árvore de jacarandá, ele me perguntou se eu seria capaz de levar a "etnografia da recusa" mais além: que tal trabalhar para informar as comunidades indígenas sobre seus direitos em recusar o compartilhamento de informações? Que tal colaborar para além da clássica divisão "pesquisador-informante"? Eu concordei. Existe um punhado de plantas e grupos de pessoas sobre os quais eu decidi não escrever, e continuo colaborando com a Comissão PróÍndio e sua irmã indígena, a Federação Nativa, no Peru. Como líder de sua comunidade e xamã, Txai Tuwe defende os direitos de propriedade intelectual dos indígenas tanto no nível local quanto no global, especialmente quando se trata da ayahuasca e do direito a usufruto exclusivo da terra pelas comunidades indígenas. Ayahuasca (Figura 6) tornou-se um nome botânico afetuoso para inúmeras disciplinas. Para as ciências psicodélicas, ela é a planta filosofal por excelência (LABATE, 2010; LABATE; CAVNER, 2014; MCKENNA, 2005; SANABRIA, 2017).

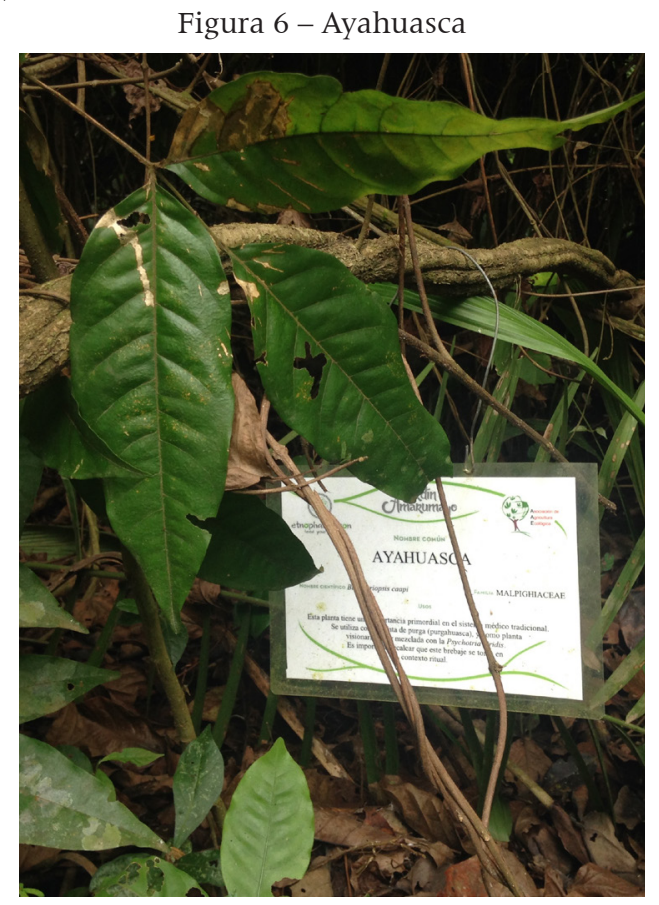

Fonte: Extraída da obra traduzida 
Para os neurobiólogos, a ayahusaca - como o principal ingrediente de uma fermentação sagrada - tornou-se objeto de análise gradativamente, desde pesquisas sobre vício (TALIN; SANABRIA, 2017) até práticas de cura da depressão (DOMÍNGUEZ-CLAVÉ et al., 2016; FROOD, 2015). Para os pesquisadores no campo do direito, a revogação da patente da ayahuasca representa um caso emblemático nas leis de propriedade intelectual (FECTEAU, 2001 ) - trata-se ainda de um exemplo sobre as preocupações crescentes em torno dos direitos de propriedade intelectual indígena (DANLEY, 2012; TUSTIN, 2006). Para os antropólogos, a ayahuasca sempre foi fonte de contemplação, senão de inebriamento (LABATE, 2010; PANTOJA, 2008; SHEPARD; YU, 2001; TAUSSIG, 1980). No Acre, a ayahuasca vem ajudando as pessoas a "reviver" seu passado indígena. Os anos brutais dos caucheros acabaram por dilacerar famílias inteiras separando-as da terra (PANTOJA, 2008; PANTOJA; MEYER, 2014). Devido ao esforço de algumas antropólogas brasileiras, como Pantoja, mas também Beatriz Labate e Alana Goldstein (2009), em reconhecer a ayahuasca como patrimônio cultural, reivindicações de identidade étnica feitas por meio da ayahuasca agora permitem acesso a pedidos de ordem territorial. Em abril de 2017, Labate organizou um simpósio de ciência psicodélica. A antropóloga Emilia Sanabria participou com uma fala intitulada "Encontros xamanísticos - Ayahuasca e as políticas do conhecimento" que me chamou atenção devido às suas preocupações serem consonantes às de líderes indígenas como Txai Tuwe. Ao falar para uma plateia academicamente diversa, Sanabria sugeriu que a antropologia possui um conjunto particular de conhecimentos que pode contribuir com uma prática de pesquisa mais colaborativa e eticamente engajada no que diz respeito à medicina baseada em plantas. A virada ontológica era o centro de sua fala. Ela detalhou como muitos acadêmicos se referem às "realidades" e à "animacidade" de diferentes formas de vida - plantas, animais, átomos $-\mathrm{e}$ "[...] levam a sério os argumentos de pessoas não-ocidentais sobre seu engajamento e relacionamentos [com não-humanos] que as ciências ocidentais não mais conseguem ver, medir ou sequer compreender" (SANABRIA, 2017). Sanabria argumentou em favor da "descolonização" da ciência a partir das ciências psicodélicas. Ela então coloca a seguinte questão: "O que é uma planta?". As várias maneiras de responder a essa pergunta expõem a divisão entre o conhecimento científico ocidental e formas de conhecer que possam ser classificadas como indígenas ou folclóricas. O argumento de Sanabria (2017) era o de que se levarmos as epistemológicas indígenas e tradicionais a sério, entrevê-se que as plantas podem ser seres sencientes, podem ter um espírito ou comunicar sabedoria, quem sabe cuidados especiais podem ser estendidos a elas; elas podem fazer parte de estruturas de parentesco. Por meio da categorização das plantas e do entrelaçamento genealógico das relações humano-plantas, Sanabria nos posicionou no encontro que ora vemos entre a antropologia e as ciências psicodélicas. A colonização faz parte da história da antropologia. E se os praticantes das ciências psicodélicas não tomarem cuidado, podem acabar seguindo uma trajetória neocolonial similar ao desconsiderar a existência de práticas e de conhecimentos xamânicos ancestrais indígenas. O motivo pelo qual os acadêmicos das ciências psicodélicas se dariam bem ao considerar outras ontologias ajuda a entender os debates intelectuais e as definições políticas em jogo dentro da antropologia. Por meio dos contínuos esforços em tentar fazer com que a antropologia norte-americana se tornasse uma ciência formalizada e 
"real" - uma ciência dura -, a história da disciplina recheou-se de anedotas como as de tentar provar sua "verdade" baseando-se em "fatos sociais". Sanabria apontou tensão semelhante nas ciências psicodélicas. Apesar da crítica ao status assumido pela psicologia e pela medicina ocidental, existe ainda o "[...] suave movimento de tornar-se legítima, de construir um regime de evidência e validação dentro das ciências hegemônicas - na verdade, antigas assunções" (SANABRIA, 2017). À medida que Sanabria desenvolvia seu argumento decolonial, ela descrevia o interesse dos xamãs e psiconautas em entender realidades sociais alternativas - como os antropólogos da virada ontológica. Ela incentivou seu público a considerar como "essa mudança está ancorada em uma reflexão crítica sobre as características coloniais, racistas e sexistas do paradigma que está substituindo". Isto é, considerar o que se chama de "novo" e para quem. Dentro do paradigma colonial dos direitos de propriedade intelectual, a semiótica da citação e da contestação da novidade para indivíduos e comunidades indígenas se materializa - ou se desfaz - nas reivindicações pela terra e na luta política. O argumento de Sanabria ecoa a declaração de Michel-Rolph Trouillot de que "[...] a história não começa com a formalização da disciplina, mas sim com a emergência do campo simbólico que permitiu tal formalização" (TROUILLOT, 2003, p. 14). Quando Trouillot escreveu "Antropologia e o Entalhe Selvagem", ele vislumbrou a antropologia se atendo ao "mito" do "bom selvagem" para encontrar novos modos e modelos de investigação ao invés de buscá-los dentro dos limites geográficos e teóricos da América do Norte (TROUILLOT, 2003, p. 13). A esperança da virada ontológica era, como diz Sanabria, a de uma abordagem disciplinar que leve seriamente em conta o modo de vida das outras pessoas no mundo, suas histórias de origem e cosmologias. Essa virada muda o "campo temático" de um modo que Trouillot acharia promissor. A preocupação que tenho com qualquer tipo de "virada" teórica na antropologia é similar à que Sanabria tem com relação às ciências psicodélicas. Refletindo sobre o trabalho de Todd (2016): se deixarmos as vozes indígenas de fora das discussões acadêmicas, qual espaço nos sobrará para refletir e impedir que o paradigma de produção de conhecimento torne-se um modelo extrativista e deletério?

\title{
4 Ressemeando o engajamento acadêmico: pensar e resistir como uma planta
}

No ensaio "Resista como uma planta! Sobre a vida vegetal dos movimentos políticos", Michael Marder (2012, p. 29) questiona:

\begin{abstract}
O que significaria ocupar os espaços públicos sem se apropriar deles? Manifestar uma multiplicidade de corpos em um local sem que necessariamente se tenha soberania sobre ele? Isso não implicaria estar em um lugar sem assumi-lo como seu, estando lá pelos outros?
\end{abstract}

Trata-se, segundo Marder, do que as plantas fazem. Eu gostaria de aproveitar as provocações de Marder sobre a "fotossíntese", para dizer que nós, humanos, estamos aqui somente por causa do reino vegetal e "não estamos sozinhos" neste mundo (MYERS, 2016). Na versão de Marder, existe ainda o risco de uma visão única da história. Habitar, mas não se apropriar do espaço, honrando as interconexões entre a vida humana e a 
não humana, tem precedentes - algo que os povos (indígenas) praticavam muito tempo antes de as caravelas europeias forçosamente aportarem em suas praias. Tensionando as questões sobre metodologia colaborativa e sobrevivência mais além: será que nós (acadêmicos europeus e norte-americanos não nativos) podemos fazer mais do que apenas imaginar espaços (citacionais) não apropriadores e será que podemos implementar tais espaços? Podem as plantas nos ajudar a pensar e a agir "fora da influência dos ritmos capitalistas", como Natasha Myers (2016) nos propõe? Sim, mas é necessário reconhecer o quão difícil é para qualquer pessoa economicamente vulnerável sair do capitalismo global, caso persigamos uma existência igualitária e colaborativa entre humanos e não humanos. A referência que Zoe Todd (2016) faz à "relacionalidade ética" do acadêmico Métis Dwayne Donald (2012) oferece sementes para ação reflexiva futura. Ao mesmo tempo que o (re)nova(do) interesse pelas relações plantas-humanos corre o risco de se desfigurar em uma apropriação do conhecimento xamânico indígena sem citá-lo propriamente, esse interesse pode também aproveitar a oportunidade deixada pelo trabalho de etnobotânicos e aqueles trabalhando na direção de uma "plantropologia" (MYERS, 2015) com vistas a reposicionar as pesquisas antropológicas ocidentais em uma rede ecológica mais ampla de relacionalidade étnica. Com o intuito de "reentrar no discurso sobre a alteridade" (TROUILLOT, 2003, p. 27), levando em consideração as ramificações políticas das citações acadêmicas, além das questões de biopirataria, é pertinente frisar a colaboração do xamã Ianomâmi Davi Kopenawa com o antropólogo francês Bruce Albert (KOPENAWA; ALBERT, 2013). As palavras de Kopenawa lembram a crença de Txai Tuwe sobre a floresta como parente, somada às suspeitas de por que os pesquisadores brancos se preocupam tanto com as árvores? As palavras para "ecologia" são nossas palavras antigas

[...]. Os xapiri (espíritos) defendem a floresta desde que ela passou a existir [...]. Será que ela não é mais tão viva quanto era antigamente? Os homens brancos que antes ignoravam todas essas coisas agora passam a escutá-las um pouco $[\ldots]$ para defender a floresta. (KOPENAWA; ALBERT, 2013, p. 393)

A esperança de Kopenawa é que, contando sua história para Albert, a "floresta permaneça viva", como sempre esteve, respondendo, assim, "[...] àqueles que perguntam a si mesmos o que os habitantes da floresta pensam" (KOPENAWA; ALBERT, 2013, p. 11). Kopenawa responde ainda à pergunta retórica feita por Txai Tuwe sobre por que os pesquisadores ocidentais ressuscitaram seu fascínio pela botânica? “Agora eles se chamam de 'ecologistas' porque ficaram com medo de ver a terra ficando cada vez mais aquecida" (KOPENAWA; ALBERT, 2013, p. 393). Portanto, ainda que haja preocupação por parte dos etnobotânicos ocidentais de que os "segredos da natureza" amazônica estejam desaparecendo e necessitam ser conhecidos, catalogados e salvos (nos mesmos padrões ocidentais), existe também o impulso disciplinar de se encontrar novos objetos de pesquisa. Txai Tuwe olha com suspeita para a antropologia norte-americana e europeia que olha para o reino vegetal em busca de novos projetos. Ele reconheceu uma nova onda, no Brasil, de extração de produção de conhecimento para exportação. Sentado embaixo do jacarandá, ele conversava sobre as colaborações com antropólogos brasileiros que permitiram demarcação de terras e apoio político. Mas ele suspeitava de outros, como eu. 
Foi apenas depois de anos de amizade que isso amainou. Não penso que poderia ter sido de outra forma. Essas suspeitas e recusa em partilhar ideias e informação são parte da bagagem antropológica que surge da preocupação com o lugar para o "entalhe selvagem".

\section{Conclusão}

Depois de nosso primeiro encontro, Txai Tuwe ganhou uma bolsa de estudos para ir estudar cinema e língua inglesa na Universidade de Nova York. Agora que se desloca recorrentemente entre Estados Unidos e Acre, ele está documentando o desenvolvimento dos rituais Huni Kuiĩ e as práticas de preservação da língua. Ele tem gravado, ainda, as manifestações políticas e os protestos que vêm acontecendo desde que Michel Temer usurpou o poder no Brasil. Não está claro ainda em que medida o atual presidente Jair Bolsonaro, apoiado pela antiga ditadura militar, permitirá alguma forma de oposição política. Como um xamã, Txai Tuwe se dirige à sua plateia norte-americana sobre as políticas que cercam a biopirataria e as práticas de uso de plantas medicinais. Desde 2016, um governo brasileiro de direita implodiu a legislação que outorgava direitos pela terra e mapeava o território político dos grupos indígenas amazônicos. Em abril de 2018, inúmeros grupos étnicos ocuparam os diversos espaços de Brasília, para protestar contra o desmonte dos seus direitos como cidadãos brasileiros. O Governo respondeu com jatos de água de alta pressão. Aqui nos lembramos das palavras de Marder (2012, p. 29): "Resistir como uma planta não é protestar com vistas a um território a ser ganho; o programa de uma limitada redistribuição de riqueza do um por cento mais rico aos pobres $[. .$.$] é inútil se deixa o princípio da apropriação intacto". A intenção de$ ocupação pacífica queria dizer: "Nós estamos aqui. Nós somos cidadãos". Sem apoio (inter)nacional os protestos arrefecem, soterrados pelos próximos eventos que capturem atenção jornalística. Baseando-se no que os cientistas e acadêmicos europeus e norteamericanos podem aprender com os protestos indígenas e com a maneira de as plantas estarem no mundo, um passo fundamental é participar de uma "ecologia decolonial", ou seja, "sermos melhores aliados dos projetos de ressurgência indígena" (MYERS, 2017b). Seja na escrita acadêmica ou nos protestos corporais, isso significa "conspirar" - isto é, "respirar com" - as plantas e as pessoas, criando "alter-relações" uns com os outros que não ignorem ou apaguem as diferenças da capacidade que o outro tem de respirar, ainda que o ar inalado não tenha a mesma qualidade (SIMMONS, 2017). Uma "etnobotânica da recusa" constitui um braço da virada etnobotânica, em uma tentativa de conspirar ao agitar atmosferas já estabelecidas (SIMMONS, 2017). Trata-se de expor e de superar os princípios de apropriação na biopirataria a nas práticas antropológicas. Referindo-se à apropriação "intacta" no campo da investigação antropológica, Audra Simpson (2007, p. 69) escreve:

Mesmo que mais aceitáveis do que no passado, as análises antropológicas da indigeneidade talvez ainda ocupem o lugar analítico do "salvamento" e do "documentário", uma elaboração do objeto que resulta da permanência de categorias que emergiram em cenários de contato colonial, muitas das quais ainda estão vigentes. 
Para desestabilizar tais categorias duráveis de análise, a colaboração entre muitos autores, a polinização cruzada e a "relacionalidade ética" são necessárias em antropologia. Finalmente, uma miríade de modos de resistência humano-implantadas virá de uma estudada reciprocidade e de escuta atenciosa das relações humano-planta.

\section{Referências}

BALICK, Michael; COX, Paul. Plants, People, and Culture: the Science of Ethnobotany. New York: Scientific American Press, 1997.

BLASER, Mario. Notes Towards a Political Ontology of 'Environmental' Conflicts. In: GREEN, L. (ed.). Contested ecologies: Dialogues in the South on nature and knowledge. Cape Town, SA: Human Sciences Research Council Press, 2013. p. 13-27.

CARNEIRO DA CUNHA, Manuela; ALMEIDA, Mauro B. de. Enciclopédia da Floresta O Alto Juruá: práticas e conhecimentos das populações. São Paulo: Companhia das Letras, 2002.

DANLEY, Vanessa. Biopiracy in the Brazilian Amazon: Learning from International and Comparative Law Successes and Shortcoming to Help Promote Biodiversity Conversation in Brazil. Florida A \& M Law Review, [s.l.], v. 7, n. 2, p. 291-327, 2012.

DE LA CADENA, Marisol. Ecologies of practice: Across Andean worlds. Durham, NC: Duke University Press, 2015.

DE LA CADENA, Marisol. Indigenous Cosmopolitics in the Andes: Conceptual Reflections Beyond politics. Cultural Anthropology, [s.l.], v. 25, n. 2, p. 334-370, 2010.

DOMínGUEZ-CLAVÉ, Elisabet et al. Ayahuasca: Pharmacology, Neuroscience and Therapeutic Potential. Brain Research Bulletin, [s.l.], v. 126, n. 1, p. 89-101, 2016.

DONALD, Dwayne. Indigenous Métissage: a Decolonizing Research Sensibility. International Journal of Qualitative Studies in Education, [s.l.], v. 25, n. 5, p. 533-555, 2012.

DUKE, James A. Handbook of Biological Active Phytochemicals \& Their Activity. Boca Raton, FL: CRC Press, 1992.

ELLSWORTH, Brian. Brazil to step up crackdown on biopiracy in 2011. Reuters, 22 December, 2010. Disponível em: https://www.reuters.com/article/us-brazil-biopiracy/brazil-to-step-upcrackdown-on-biopiracy-in-2011-idUSTRE6BL37820101222. Acesso em: 31 ago. 2021.

FABRICANT, Daniel; FARNSWORTH, Norman. The Value of Plants Used in Traditional Medicine for Drug Discovery. Environmental Health Perspectives, [s.l.], v. 109, n. 1, p. 69-75, 2001.

FECTEAU, Leanne M. The Ayahuasca Patent Revocation: Raising Questions About Current US Patent Policy. Boston College Third World Law Journal, [s.l.], v. 21, n. 1, p. 69-104, 2001.

FROOD, Arran. Ayahuasca Psychedelic Tested for Depression. Nature, 6 April, 2015. Disponível em: http://dx.doi.org/10.1038/ nature.2015.17252. Acesso em: 31 ago. 2021.

GOLDSTEIN, Ruth. An Ecology of the Self and Other Wild Thoughts. 2009. 127 p. Masters (Thesis) - University of California, Berkeley, 2009.

GOLDSTEIN, Ruth. The Philosopher Plant and the Scientist's Specimen. Ethnos, 2020. DOI: 10.1080/00141844.2019.1631872.

HALL, Matthew. Plants as Persons: a Philosophical Botany. Albany: SUNY Press, 2011.

HARAWAY, Donna. When species meet. Minneapolis: University of Minnesota Press, 2007. 
HARTIGAN, John. How to interview a plant. In: HARTIGAN, John. Care of the Species: Races of Corn and the Science of Plant Biodiversity. Minneapolis: University of Minnesota Press, 2017. p. 253-281.

HOOVER, Elizabeth. The River Is In Us: Fighting Toxics in a Mohawk Community. Minneapolis: University of Minnesota Press, 2017.

INDRIUNAS, Luís. Biopirataria: o Brasil se defende. Abril online, 2003. Disponível em: https://super.abril.com. br/cultura/biopirataria-o- brasil-se-defende/. Acesso em: 2 set. 2021.

KIMMERER, Robin. Braiding sweetgrass: Indigenous wisdom, scientific knowledge, and the teachings of plants. Minneapolis: Milkweed Editions, 2013.

KIRKSEY, Eben; HELMREICH, Stephen. The Emergence of Multispecies Ethnography. Cultural Anthropology, [s.l.], v. 25, n. 4, p. 545-576, 2010.

KOPENAWA, David; ALBERT, Bruce. The Falling Sky: Notes from a Yanomami Shaman. (Trans.) N. Elliott and A. Dundy. Cambridge: University of Harvard Press, 2013.

KOSEK, Jake. Ecologies of Empire: on the New Uses of the Honeybee. Cultural Anthropology, [s.l.], v. 25, n. 4, p. 650-678, 2010.

LABATE, Beatriz C. As Religiões Ayahuasqueiras, Patrimônio Cultural, Acre e Fronteiras Geográficas. Ponto Urbe 7, 2010. Disponível em: http:// pontourbe.revues.org/1640. Acesso em: 31 ago. 2021.

LABATE, Beatriz C. Ayahuasca Religions in Acre: Cultural Heritage in the Brazilian Borderlands. Anthropology of Consciousness, [s.l.], v. 23, n. 1, p. 87-102, 2012.

LABATE, Beatriz C.; CAVNER, Clancy; FREEDMAN, Françoise B. Notes on the Expansion and Reinvention of Ayahuasca Shamanism. In: LABATE, Beatriz C.; CAVNER, Clancy. Shamanism in the Amazon and Beyond. Oxford: Oxford Online Scholarship, 2014. Disponível em: https:// oxford.universitypressscholarship.com/view/10.1093/acprof:oso/9780199341 191.001.0001/acprof9780199341191-chapter-1. Acesso em: 1º set. 2021.

LABATE, Beatriz C.; GOLDSTEIN, Ilan. Ayahuasca: From Dangerous Drug to National Heritage: An interview with Antonio A. Arantes. International Journal of Transpersonal Studies, [s.l.], v. 28, p. 53-64, 2009.

LAPIER, Rosalyn. Blackfeet botanist. Montana Naturalist, [s.l.], p. 4-5, 2005.

LAPIER, Rosalyn. Smudging: Plants, Purification and Prayer. Montana Naturalist, [s.l.], v. 16-17, 2016.

MARDER, Michael. Resist Like a Plant! On the Vegetal Life of Political Movements. Peace Studies Journal, [s.l.], v. 5, n. 1, p. 24-32, 2012.

MARDER, Michael. Plant Thinking: a Philosophy of Vegetal Life. New York: Columbia University Press, 2013.

MARDER, Michael. The Philosopher's Plant: An Intellectual Herbarium. New York: Columbia University Press, 2014.

MCKENNA, Douglas. Ayahuasca and human destiny. Journal of Psychoactive Drugs, [s.l.], v. 37, n. 2, p. 231-234, 2005.

MYERS, Natasha. Conversations on Plant Sensing Notes from the Field. Nature Culture, [s.l.], p. 35-36, 2015.

MYERS, Natasha. Photosynthesis. Theorizing the Contemporary. Cultural Anthropology, [s.l.], 21 January, 2016. Disponível em: http://culanth. org/fieldsights/790- photosynthesis. Acesso em: $1^{\circ}$ set. 2021.

MYERS, Natasha. From the Anthropocene to the Planthroposcene: Designing Gardens for Plant/People Involution. History and Anthropology, [s.l.], p. 1-5, 2017 a. 
MYERS, Natasha. Ungrid-able Ecologies: Decolonizing the Ecological Sensorium in a 10,000 Year-Old Naturalcultural Happening. Catalyst: Feminism, Theory, Technoscience, [s.l.], v. 3, n. 2, p. 1-24, 2017b.

PANTOJA, Mariana C. Os Milton: cem anos de história nos Seringais. Rio Branco: Edufac, 2008.

PANTOJA, Mariana C.; MEYER, Matthew. Kuntanawa: Ayahuasca, ethnicity, and culture. In: B. LABATE, B.; CAVNER, C. Ayahuasca shamanism in the Amazon and beyond. (Trans.) M. Meyer. Oxford: Oxford University Press Online, 2014. Disponível em: https://oxford. universitypressscholarship.com/view/10.1093/acprof:oso/9780199341191.001.0001/acprof9780199341191-chapter-3. Acesso em: $1^{\circ}$ set. 2021.

SALMÓN, Enrique. Kincentric Ecology: Indigenous Perceptions of the Human-Nature Relationship. Traditional Ecological Knowledge, [s.l.], v. 10, n. 5, p. 1.327-1.332, 2000.

SANABRIA, Emilia. Healing Encounters: Ayahuasca and the Politics of Knowledge. Paper given at the Psychedelic Science 2017 conference, Oakland, CA, 2017. Disponível em: https://2017.psychedelicscience.org/conference/plant-medicine/healing-encounters-ayahuascaand-the-politics-of-knowledge. Acesso em: 31 ago. 2021.

SCHMIDLEHNER, Michael F. Biopirataria: Fim da Vista? Revista Jurídica Consulex, [s.l.], p. $31-33,2011$.

SCHULTHIES, Becky. Partitioning, phytocommunicability, and plant pieties. Anthropology Today, [s.l.], 2019.

SHEPARD, Glenn; YU, Douglas. Conocimientos Tradicionales, Biodiversidad y Alternativas Para el Desarrollo en la Amazonía. In: RODRIGUEZ, L. (ed.). Manu y otras experiencias de investigación y manejo de bosques neotropicales. Lima: Pro-Manu/Gobierno del Perú/ Unión Europea, 2001. p. 189-195.

SHIVA, Vandana. Biopiracy: the Plunder of Nature and Knowledge. Berkeley, CA: North Atlantic Books, 1997.

SIMMONS, Kristen. Settler atmospherics. Cultural Anthropology, 2017. Disponível em: https://culanth.org/fieldsights/1221-settler-atmospherics. Acesso em: 31 ago. 2021.

SIMPSON, Audra. On ethnographic refusal: Indigeneity, 'voice' and colonial citizenship. Junctures [s.l.], v. 9, p. 67-80, 2007.

TALIN, Peter; SANABRIA, Emilia. Ayahuasca's Entwined Efficacy: an Ethnographic Study of Ritual Healing from Addiction. International Journal of Drug Policy, [s.l.], v. 44, p. 23-30, 2017.

TAUSSIG, Michael. The Devil and Commodity Fetishism in South America. Durham: University of North Carolina Press, 1980.

TODD, Zoe. An Indigenous Feminist's Take on the Ontological Turn: Ontology is Just Another Word for Colonialism. Journal of Historical Sociology, [s.l.], v. 29, n. 1, p. 4-22, 2016.

TROUILLOT, Michel R. Anthropology and the Savage Slot: the Politics and Poetics of otherness. In: TROUILLOT, Michel R. Global transformations: Anthropology and the Modern World. New York: Palgrave, 2003. p. 7-28.

TSING, Anna. The Mushroom at the End of the World: on the Possibility of Life in Capitalist Ruins. Princeton: Princeton University Press, 2015.

TUSTIN, John. Traditional Knowledge and Intellectual Property in Brazilian Biodiversity Law. Texas Intellectual Property Law Journal, [s.l.], v. 14, p. 131-157, 2006.

VIVEIROS DE CASTRO, Eduardo. Perspectivismo e multinaturalismo na América indígena. O que nos faz pensar, [s.l.], v. 18, p. 225-254, 2004.

VIVEIROS DE CASTRO, Eduardo. Cannibal metaphysics. Minnesota: University of Minnesota Press, 2014. 
WHYTE, Kyke P. On the Role of Traditional Ecological Knowledge as a Collaborative Concept: A Philosophical Study. Ecological Processes, [s.l.], v. 2, n. 7, p. 1-12, 2013.

* Este artigo foi publicado originalmente como GOLDSTEIN, Ruth. Ethnobotanies of Refusal: Methodologies in Respecting Plant(ed)-Human Resistance. Special Issue on Plant

Ethnography, Anthropology Today, [s.l.], v. 35, n. 2, p. 18-22, 2019.

\section{Ruth Goldstein}

Doutora em Antropologia pela Universidade de Califórnia, Berkeley. Professora Assistente e pesquisadora no Departamento de Estudos em Gênero, Mulheres e Sexualidade, na Universidade de Wisconsin, Madison.

Endereço profissional: Departamento de Estudos em Gênero, Mulheres e Sexualidade, 475, North Charter Street, Madison, WI 53711, EUA.

E-mail: ruth.goldstein@wisc.edu

ORCID: https://orcid.org/0000-0003-1969-6450

\section{Daniel Belik (Tradutor)}

Pós-Doutorando em Geografia pela Universidade Federal de Rondônia (UNIR). Foi assistente de projetos para questões indígenas na Organização Internacional para as Migrações das Nações Unidas (OIM/ ONU). Doutor em Antropologia Social pela University of St. Andrews e Mestre em Antropologia Social pela University of Aberdeen, na Escócia. Graduado em Ciências Sociais pela Universidade de São Paulo e Licenciado pela Faculdade de Educação da mesma universidade. Trabalhou na Coordenação de Gestão Ambiental e Territorial Indígena (CGGAM) da FUNAI, em Brasilia. Foi Professor Substituto no Centro de Educação, Artes e Letras da Universidade Federal do Acre (CELA/UFAC). Presta consultoria como antropólogo para Organizações Governamentais, Não Governamentais, Indígenas e Internacionais, especialmente na Amazônia.

Endereço profissional: Fundação Universidade Federal de Rondônia, BR-364, n. 9, Cidade Jardim, Porto Velho, RO. CEP: 78900-000.

E-mail:dbbelik@gmail.com

ORCID: https://orcid.org/0000-0001-6020-6113

\section{Daniel do Nascimento e Silva (Revisor de tradução)}

Professor de pragmática, linguística aplicada e sociolinguística da Universidade Federal de Santa Catarina e do Programa Interdisciplinar em Linguística Aplicada da Universidade Federal do Rio de Janeiro. Desenvolve pesquisas sobre significação, violência e resistência política a partir de pesquisa de campo no Complexo do Alemão/RJ e outros territórios. É co-editor de Trabalhos em Linguística Aplicada e Pragmatics. É editor associado de DELTA e membro do comitê editorial de Language in Society. Em 2021, coeditou, com Jacob Mey, o livro "The pragmatics of Adaptability" (John Benjamins).

Endereço profissional: Departamento de Língua e Literatura Vernáculas, Campus Universitário Trindade, UFSC, Centro de Comunicação e Expressão, Bloco B, Sala 201-B, Caixa Postal 476, Florianópolis, SC. Cep: 88040-900.

E-mail:dnsfortal@gmail.com ou daniel.ns@ufsc.br

ORCID: https://orcid.org/0000-0002-6098-5185

\section{Como referenciar este artigo:}

GOLDSTEIN, Ruth. Tradução: Etnobotânicas da Recusa: Metodologias de Engajamento com a Resistência Humana-Implantada. Tradução de Daniel Belik e revisão de Daniel Silva. Ilha Revista de Antropologia, Florianópolis, v. 23, n. 3, p. 197-213, setembro de 2021. 